\title{
PENGEMBANGAN SUMBER DAYA MANUSIA DALAM ANALISIS AKTIVASI NEUTRON DI BATAN
}

\author{
Yustina Tri Handayani \\ Pusat Pendidikan dan Pelatihan BATAN, Jakarta, Indonesia \\ yustina@batan.go.id
}

\begin{abstract}
ABSTRAK
PENGEMBANGAN SUMBER DAYA MANUSIA DALAM ANALISIS AKTIVASI NEUTRON DI BATAN. Analisis Aktivasi Neutron (AAN) memiliki sensitivitas tinggi dan merupakan kompetensi BATAN. Pemetaan pengembangan sumber daya manusia yang sudah dilakukan untuk personel AAN diperlukan sebagai dasar untuk mempertahankan dan mengembangkan kompetensi BATAN. Kelompok AAN di BATAN terdiri dari 3 kelompok utama dan 6 kelompok pendukung. Pengembangan SDM AAN dilakukan melalui Pelatihan, Sertifikasi Personel, Uji Banding, Seminar, Workshop, Pertemuan Teknis, dan e-learning. Sejak tahun 2003 telah diselenggarakan 9 Pelatihan AAN. Pada tahun 2009 diluncurkan Standar BATAN No. 007-BATAN: 2009 tentang Pedoman Kualifikasi dan Sertifikasi Petugas AAN. Pelatihan untuk Petugas AAN dirangkai dengan sertifikasi personel mensertifikasi petugas baru dan sertifikasi ulang untuk 21 Teknisi Preparasi Sampel, 23 Teknisi Spektrometer Gamma, dan 8 Penyelia. Uji banding AAN secara internal diselenggarakan dari tahun 2008 sampai dengan 2015. Pada tingkat nasional dan internasional, beberapa laboratorium mengikuti Uji Banding yang diselenggarakan oleh KAN, ANSTO, dan IAEA. Hasil Uji Banding menunjukkan peningkatan kinerja secara signifikan, setelah diselenggarakan Pelatihan dan Sertifikasi Personel. Pada tahun 2016 IAEA meluncurkan e-learning AAN yang bisa dimanfaatkan baik dalam Pelatihan AAN, maupun pengembangan kompetensi Petugas AAN. Seminar, pertemuan teknis dan workshop diselenggarakan untuk meningkatkan pemahaman terhadap topik tertentu. Pengembangan SDM melalui pelatihan, sertifikasi personel, uji banding, seminar, pertemuan teknis secara berkesinambungan dapat mempertahankan dan meningkatkan kompetensi yang sudah ada.
\end{abstract}

Kata kunci : analisis aktivasi neutron, e-learning, pelatihan, sumber daya manusia

\begin{abstract}
HUMAN RESOURCES DEVELOPMENT OF NEUTRON ACTIVATION ANALYSIS IN BATAN. Neutron Activation Analysis (NAA) is one of the methods with high sensitivity that is a BATAN competency. The mapping of human resource development that has been carried out for NAA personnels is needed as a basis for maintaining and developing BATAN competency. The NAA groups in BATAN consists of 3 main groups and 6 supporting groups. NAA Human Resources development is carried out through Training, Personnel Certification, Proficiency Test, Seminars, Workshops and Technical Meetings. Nine NAA trainings were conducted since 2003. In 2009, BATAN Standard No. 007-BATAN: 2009 concerning Guideline of NAA Officer Qualification and Certification was launched. Training for NAA Personnel, followed by certification of personnel, certified new officers and re-certified 21 Technicians of Sample Preparation, 23 Technicians of Gamma Spectrometer, and 8 Supervisors. The NAA proficiency test, internally held from 2008 through 2015. Several laboratories participated in the Proficiency Test held by the National Accreditation Committee, ANSTO and IAEA. Proficiency Test Results showed a significant improvement in performance after participation in Training and Certification of Personnel. In 2016 IAEA launched the e-learning tool of NAA that can be utilized both in NAA Training, and the development of NAA personnel competencies. The seminars, technical meetings and workshops were also held to increase understanding of certain topics. Human resources development through training, personnel certification, proficiency tests, seminars, technical meeting, and workshops are recommended to maintain and improve existing competencies especially when conducted in continuous manner.
\end{abstract}

Keywords : e-learning, human resources, neutron activation analysis, training 


\section{PENDAHULUAN}

Analisis Aktivasi Neutron (AAN) merupakan metode analisis unsur yang memiliki sensitivitas tinggi, sehingga diterapkan antara lain untuk analisis unsur mikro dalam sampel tanah, partikulat udara, dan bahan makanan. AAN berdasarkan pada reaksi inti berupa penangkapan neutron. Reaksi inti dengan neutron dapat dilakukan dalam reaktor nuklir dengan daya kecil sampai sedang. Cuplikan dan standar yang sudah diiradiasi diukur menggunakan spektrometer gamma. Berdasarkan spektrum hasil pengukuran, analisis terhadap cuplikan dilakukan secara kualitatif untuk menentukan unsurnya, dan secara kuantitatif untuk menentukan nilai konsentrasinya.

Tahap pelaksanaan AAN meliputi preparasi sampel, iradiasi sampel, pengukuran sampel, serta analisis kualitatif dan kuantitatif. Berdasarkan unsur yang akan dianalisis, dalam preparasi sampel dilakukan penentuan jenis standar, massa, dan waktu iradiasi. Iradiasi di reaktor nuklir dilaksanakan sesuai dengan kebutuhan oleh Petugas dari reaktor nuklir. Dalam pengukuran sampel menggunakan spektrometer gamma ditentukan posisi pengukuran, urutan pengukuran, waktu pengukuran sesuai dengan kriteria spektrum yang bisa dianalisis dengan mempertimbangkan deadtime dan limit deteksi puncak. Peralatan preparasi dan spektrometer gamma diuji dan dikalibrasi secara berkala sesuai ketentuan yang berlalu untuk memastikan peralatan memiliki unjuk kerja yang memadai. Pelaksanaan analisis membutuhkan personel yang memiliki kompetensi memadai, supaya hasil analisis dapat dipertanggungjawabkan.

Di Badan Tenaga Nuklir Nasional (BATAN), kegiatan AAN dilakukan oleh 3 kelompok utama di tiga satuan kerja, yaitu di Pusat Sains dan Teknologi Bahan Maju (PSTBM) di Serpong, Pusat Sains dan Teknologi Nuklir Terapan (PSTNT) di Bandung, dan Pusat Sains dan Teknologi Akselerator (PSTA) di Yogyakarta.

Kompetensi personel AAN menentukan kinerja kelompok atau laboratorium, sehingga pengembangan sumber daya manusia (SDM) secara terstruktur dan sistematis diperlukan untuk mencapai kinerja yang diharapkan. Pengembangan SDM dalam AAN dilakukan melalui pelatihan, sertifikasi personel, uji banding, seminar, workshop, dan pertemuan teknis. Pemetaan pengembangan sumber daya manusia yang sudah dilakukan dalam kegiatan AAN diperlukan sebagai dasar untuk mempertahankan dan mengembangkan kompetensi BATAN.

\section{METODE}

\section{Pelatihan}

Pelatihan merupakan upaya sistematis untuk mencapai kompetensi tertentu. Kurikulum Pelatihan disusun berdasarkan kompetensi yang akan dicapai. Pelatihan AAN diselenggarakan oleh Pusat Pendidikan dan Pelatihan (Pusdiklat) dari tahun 2003 sampai dengan 2017, seperti ditunjukkan pada Tabel 1 [1-9].

Tabel 1. Pelatihan AAN

\begin{tabular}{|c|c|c|}
\hline Waktu & $\begin{array}{c}\text { Nama } \\
\text { Pelatihan }\end{array}$ & Jumlah Peserta \\
\hline $\begin{array}{l}27 \text { Oktober }-7 \\
\text { November } \\
2003 \\
\end{array}$ & $\begin{array}{l}\text { Penyelia } \\
\text { Laboratorium } \\
\text { AAN }\end{array}$ & 14 \\
\hline $\begin{array}{l}20 \text { November - } \\
1 \text { Desember } \\
2006 \\
\end{array}$ & $\begin{array}{l}\text { Metode AAN } \\
\mathrm{K}_{0}\end{array}$ & 19 \\
\hline $\begin{array}{l}27 \text { Agustus - } 7 \\
\text { September } \\
2007\end{array}$ & $\begin{array}{l}\text { Validasi } \\
\text { Metode AAN } \\
\mathrm{K}_{0}\end{array}$ & 20 \\
\hline $\begin{array}{l}6 \text { April - } 30 \\
\text { Juni } 2009\end{array}$ & $\begin{array}{l}\text { Coaching: } \\
\text { Komputasi } \\
\text { Pemodelan } \\
\text { AAN } \\
\text { Instrumental } \mathrm{K}_{0}\end{array}$ & $\begin{array}{c}9 \\
\text { (Pusat } \\
\text { Pengembangan } \\
\text { Informatika } \\
\text { Nuklir) }\end{array}$ \\
\hline $\begin{array}{l}23 \text { November - } \\
23 \text { Desember } \\
2009\end{array}$ & $\begin{array}{l}\text { Coaching: } \\
\text { Validasi } \\
\text { Metode AAN }\end{array}$ & $\begin{array}{c}6 \\
\text { (Pusdiklat) }\end{array}$ \\
\hline $\begin{array}{l}4-15 \text { Juli } \\
2011\end{array}$ & $\begin{array}{l}\text { Pelatihan } \\
\text { untuk Teknisi } \\
\text { AAN }\end{array}$ & 27 \\
\hline $\begin{array}{l}5-19 \\
\text { November } \\
2012\end{array}$ & $\begin{array}{l}\text { Pelatihan untuk } \\
\text { Penyelia AAN }\end{array}$ & 12 \\
\hline $\begin{array}{l}16-20 \\
\text { November } \\
2015\end{array}$ & $\begin{array}{l}\text { Penyegaran } \\
\text { untuk Petugas } \\
\text { AAN (Teknisi } \\
\text { dan Penyelia) }\end{array}$ & 10 \\
\hline $\begin{array}{l}24 \text { Juli }-8 \\
\text { Agustus } 2017\end{array}$ & $\begin{array}{l}\text { Penyegaran } \\
\text { untuk Petugas } \\
\text { AAN (Teknisi } \\
\text { dan Penyelia) }\end{array}$ & 15 \\
\hline
\end{tabular}

Penyampaian materi dalam Pelatihan AAN yang diselenggarakan pada tahun 2003 
sampai dengan 2015 dilakukan secara tatap muka dengan metode ceramah, praktikum, dan diskusi. Sedangkan pada pelatihan tahun 2017 penyampaian materi dilakukan secara $e$ learning dan tatap muka.

\section{SB 007-BATAN: 2009}

Standar Batan No. 007-BATAN: 2009 disusun dengan tujuan petugas AAN memiliki kompetensi sesuai dengan kualifikasinya, sehingga mampu melaksanakan proses dengan baik sesuai dengan standar yang ditetapkan. Personel yang disertifikasi berdasarkan standar tersebut diklasifikasikan dalam salah satu dari dua tingkat sebagai berikut [10]:

1. Teknisi preparasi sampel dengan tugas/ kewenangan:
a. mempersiapkan (set-up) peralatan pre- parasi sampel;
b. mengoperasikan peralatan preparasi sampel;
c. melakukan preparasi sampel dan standar;
d. merekam hasil proses preparasi sampel;
e. melaporkan hasil preparasi sampel;
f. mempersiapkan sampel dan standar untuk proses iradiasi;
g. memelihara kinerja peralatan yang digunakan.

2. Teknisi spektrometer gamma dengan tugas/ kewenangan
a. menentukan waktu iradiasi sampel;
b. merekam proses iradiasi sampel;
c. melakukan penanganan sampel paska iradiasi;
d. mempersiapkan (set-up) dan meng- operasikan spektrometer gamma;
e. mengukur dan merekam data;
f. melaporkan hasil pengukuran;
g. memelihara kinerja spektrometer gamma.

3. Penyelia AAN dengan tugas/kewenangan:
a. mengemban tanggung jawab penuh terhadap teknis pelaksanaan AAN;
b. melakukan penyeliaan pekerjaan teknisi;
c. menyediakan instruksi kerja untuk teknisi;
d. merancang dan menentukan parameter analisis;
e. melakukan analisis kualitatif dan

f. melakukan interpretasi dan evaluasi hasil;

g. melaporkan hasil.

Untuk mengikuti sertifikasi personel, calon Petugas AAN harus memenuhi persyaratan minimum mengenai kesehatan, pendidikan, pelatihan dan pengalaman dalam proses AAN, serta wajib mengikuti Pelatihan sesuai klasifikasi. Pusdiklat menyelenggarakan pelatihan untuk Teknisi dan Penyelia dengan durasi masing-masing 82 Jam Pelajaran sesuai kurikulum yang sudah ditentukan dalam Standar BATAN tersebut. Calon Penyelia AAN harus mempunyai pengalaman sebagai Teknisi Preparasi Sampel dan Teknisi Spektrometer Gamma [10].

Ujian serifikasi diselenggarakan oleh Pusat Sertifikasi Personel yang menjadi tanggung jawab Pusat Standarisasi Mutu Nuklir (PSMN). Penilaian mengacu pada kriteria yang dinyatakan dalam Tabel 2. Nilai kelulusan $70 \%$ untuk ujian tertulis (umum dan spesifik), maupun ujian praktek [10].

Tabel 2. Kriteria Penilaian

\begin{tabular}{lcc}
\hline \multirow{1}{*}{ Subyek } & \multicolumn{2}{c}{ Faktor bobot (\%) } \\
\cline { 2 - 3 } & Teknisi & Penyelia \\
\hline $\begin{array}{l}\text { Pengetahuan tentang } \\
\text { peralatan, termasuk fungsi, } \\
\text { persiapan (set- up }\end{array}$ & 25 & 15 \\
$\begin{array}{l}\text { pengoperasian dan } \\
\text { perawatan }\end{array}$ & & \\
\hline $\begin{array}{l}\text { Pelaksanaan praktek } \\
\text { preparasi / spektrometri } \\
\text { gamma }\end{array}$ & 60 & 15 \\
\hline Analisis dan evaluasi hasil & - & 55 \\
\hline Pelaporan hasil & 15 & 15 \\
\hline
\end{tabular}

Masa berlaku sertifikasi selama 5 tahun. Sertifikasi ulang dilakukan dengan mengikuti ujian kualifikasi seperti sertifikasi baru [10].

\section{Uji Banding}

Program Uji Banding AAN diselenggarakan dengan tujuan untuk meningkatkan kemampuan Laboratorium AAN dalam melaksanakan analisis. Uji Banding internal BATAN diselenggarakan sebanyak 7 kali dari tahun 2008 sampai dengan 2015 [11-16].

Penilaian hasil uji Banding mengacu pada Uji Profisiensi yang dilakukan oleh Badan Tenaga Atom Internasional (International Atomic Energy Agency, IAEA), 
dengan menggunakan uji statistik bias relatif, u-test score, akurasi dan presisi, sebagai berikut [11-16]:

\section{Bias relatif}

$$
\text { Bias relatif }=\frac{\text { nilai }_{\text {analis }}-\text { nilai }_{\text {sertifikat }}}{\text { nilai }_{\text {sertifikat }}}
$$

2. Rasio

$$
\text { Ratio }=\frac{\text { nilai }_{\text {analis }}}{\text { nilai }_{\text {sertifikat }}}
$$

3. $\mathrm{u}_{\text {test }}$

$$
u_{\text {test }}=\frac{\mid \text { nilai }_{\text {sertifikat }}-\text { nilai }_{\text {analis }} \mid}{\sqrt{u n c_{\text {sertifikat }}^{2}-u n c_{\text {analis }}^{2}}}
$$

4. Akurasi: Hasil Pengujian diterima, apabila $\mathrm{A} \leq \mathrm{B}$

$$
\begin{aligned}
& A=\mid \text { nilai }_{\text {sertifikat }}-\text { nilai }_{\text {analis }} \mid \\
& B=1,95 \times \sqrt{u n c_{\text {sertifikat }}^{2}+u n c_{\text {analis }}^{2}}
\end{aligned}
$$

5. Presisi: Hasil pengujian diterima, apabila $\mathrm{C} \leq \mathrm{D}$

$$
\begin{aligned}
& C=\sqrt{\left[\left(\frac{u n c_{\text {sertifikat }}}{\text { nilai }_{\text {sertifikat }}}\right)^{2}+\left(\frac{u n c_{\text {analis }}}{\text { nilai }_{\text {analis }}}\right)^{2}\right] \times 100 \%} \\
& D=\sqrt{\left[\left(\frac{u n c_{\text {sertifikat }}}{\text { nilai }_{\text {sertifikat }}}\right)^{2}+\left(\sigma_{H}\right)^{2}\right] \times 100 \%} \\
& \sigma_{H}=0,02 \times c^{0,8495}
\end{aligned}
$$

Keterangan:

$\begin{array}{ll}\text { unc } & \text { : nilai ketidakpasatian } \\ \mathrm{c} & : \text { fraksi konsentrasi } \\ \sigma_{\mathrm{H}} & : \text { prediksi Horwitz }\end{array}$

Hasil pengujian diterima, jika akurasi dan presisi memenuhi kriteria.

Beberapa laboratorium mengikuti Uji Banding eksternal, yaitu yang diselenggarakan oleh:

1. Komite Akreditasi Nasional

Uji banding ini diikuti secara rutin oleh beberapa laboratorium AAN dari kelompok utama yang mendapat sertifikasi dari KAN sebagai laboratorium uji berdasarkan ISO 17025;
2. Australian Nuclear Science and Technology Organisation (ANSTO, 2013);

3. IAEA (2014-2015).

\section{Pertemuan Teknis, Workshop dan Seminar}

Pertemuan teknis diselenggarakan untuk pembahasan topik tertentu, seperti:

1. hasil uji banding;

2. ketidakpastian pengukuran;

3. limit deteksi;

4. skema waktu iradiasi, waktu pendinginan, dan waktu iradiasi;

5. penerapan metode $\mathrm{K}_{0}$.

Pertemuan teknis selama 1-2 hari diikuti oleh personel yang secara langsung terlibat melakukan analisis.

Workshop juga diselenggarakan untuk pembahasan topik tertentu dengan topik yang lebih luas, seperti:

1. Utilization of Nuclear Reactor;

2. Pengembangan AAN Epithermal.

Beberapa workshop mengundang expert IAEA sebagai narasumber.

Seminar Nasional Teknik Analisis Nuklir (TAN) mewadahi topik AAN, analisis radioaktivitas lingkungan, analisis perpendaran sinar-X (XRF, X-ray fluororecense). Personel yunior AAN didorong untuk terlibat menyajikan makalah, baik sebagai penulis utama maupun kedua, sehingga dapat meningkatkan kerjasama personel senior dan yunior. Pada saat kegiatan seminar, personel memperoleh tambahan wawasan dari penyajian dan pembahasan oleh pembicara kunci dan penyaji makalah.

\section{e-Learning AAN}

Sebagian besar reaktor riset di dunia yang berjumlah 246 reaktor digunakan untuk kegiatan AAN yang bisa memberikan keuntungan secara komersial untuk jasa reaktor riset. Observasi yang dilakukan oleh IAEA menunjukkan bahwa banyak personel AAN yang sudah memasuki masa pensiun, sehingga menimbulkan kesenjangan pengetahuan aspek metodologi dan metrologi teknik AAN dalam tim yang tersisa maupun personel baru. Oleh karena itu, preservasi dan manajemen pengetahuan dalam jaminan dan kendali mutu serta automatisasi AAN merupakan faktor 
kunci untuk kesinambungan teknik analisis yang banyak memiliki kelebihan tersebut. IAEA mengambil langkah untuk merancang dan mengembangkan e-learning tool of Neutron Activation Analysis (NAA), yang diluncurkan pada tahun 2016 [17].

\section{HASIL DAN PEMBAHASAN}

\section{Pelatihan dan Sertifikasi Personel}

Pusdiklat dan PSMN mendukung kegiatan AAN melalui penyelenggaraan pelatihan dan sertifikasi Personel. Pusat lain yang terlibat dalam kegiatan AAN adalah:

1. Pusat Aplikasi Isotop dan Radiasi (PAIR), memanfaatkan AAN untuk analisis sampel lingkungan dan biologi;

2. Pusat Teknologi Keselamatan dan Metrologi Radiasi (PTKMR), dengan keterlibatan pada unjuk kerja spektrometer gamma;

3. Sekolah Tinggi Teknologi Nuklir (STTN), membekali pengajar dengan perkembangan AAN;

4. Pusat Teknologi Bahan Galian Nuklir (PTBGN), memanfaatkan AAN untuk analisis sampel mineral.

Pusdiklat juga menyelenggarakan Pelatihan Radiokimia untuk mahasiswa, sehingga membutuhkan pembimbing praktikum AAN.

Mulai tahun 2011, Pelatihan AAN diselenggarakan menjadi satu rangkaian dengan sertifikasi Petugas AAN, seperti ditunjukkan pada Tabel 3.

Tabel 3. Jumlah petugas AAN tersertifikasi

\begin{tabular}{lll}
\hline Tahun & Nama Pelatihan & Serifikasi Personel \\
\hline 2011 & Pelatihan untuk & 15 Teknisi PS \\
& Teknisi AAN & 19 Teknisi SG \\
\hline 2012 & Pelatihan untuk & 6 Penyelia \\
& Penyelia AAN & \\
\hline 2015 & Penyegaran untuk & Sertifikasi baru: \\
& Petugas AAN (Teknisi & 1 Teknisi PS \\
& dan Penyelia) & 1 Teknisi SG \\
& & 1 Penyelia \\
& & Resertifikasi: \\
& & 5 Teknisi PS \\
& & 2 Teknisi SG \\
\hline 2017 & Penyegaran untuk & Sertifikasi baru: \\
& Petugas AAN (Teknisi & 11 Teknisi PS \\
& dan Penyelia) & 11 Teknisi SG \\
& & 1 Penyelia \\
& & Resertifikasi: \\
\hline
\end{tabular}

3 Penyelia

Keterangan:

PS: Preparasi Sampel

SG: Spektrometer Gamma

Kurikulum dan silabi Pelatihan disusun oleh para pengajar mengacu pada SB BATAN007: 2009. Para pengajar terdiri dari personel senior yang sudah berkecimpung lebih dari 20 tahun dalam AAN, dan dibantu personel senior dari satuan kerja lain untuk materi Iradiasi, Spektrometer Gamma, dan Standar BATAN. Sertifikasi diselenggarakan oleh PSMN dengan Tim Penguji terdiri dari personel senior AAN.

Sertifikasi baru dan sertifikasi ulang sudah dilakukan terhadap 21 Teknisi Preparasi Sampel, 23 Teknisi Spektrometer Gamma, dan 8 Penyelia. Jumlah Petugas AAN yang masih aktif terdiri dari 13 Teknisi Preparasi Sampel, 13 Teknisi Spektrometer Gamma, dan 5 Penyelia. Teknisi tersebar di 8 satuan kerja, sedangkan Penyelia AAN ada di 3 kelompok utama AAN.

\section{Hasil Uji Banding}

Jenis sampel, jenis unsur, dan keikutsertaan laboratorium dalam Uji Banding (UB) ditunjukkan pada Tabel 4. Jenis sampel dan unsur yang ditentukan dalam Uji Banding, dari tahun ke tahun meningkat tingkat kesulitannya. Unsur kategori A memiliki tingkat kesulitan yang lebih rendah dibandingkan kategori B [11-16].

Hasil Uji Banding oleh laboratorium ditunjukkan pada Gambar 1. Grafik menunjukkan kecenderungan peningkatan hasil Uji Banding 1 sampai dengan Uji Banding 6 oleh 6 laboratorium. Peningkatan secara signifikan terlihat pada UB-5 dan UB-6 yang dilakukan setelah personel AAN mengikuti Pelatihan pada tahun 2012. Hal tersebut menunjukkan peningkatan kompetensi personel melalui pelatihan dan sertifikasi personel sangat mendukung peningkatan kompetensi laboratorium. Hasil Uji Banding eksternal juga menunjukkan hasil yang setara. 
Tabel 4. Uji Banding Internal

\begin{tabular}{|c|c|c|c|}
\hline Tahun & Sampel & Unsur & $\begin{array}{l}\text { Keikut- } \\
\text { sertaan }\end{array}$ \\
\hline $\begin{array}{l}2008- \\
2009\end{array}$ & $\begin{array}{l}\text { tanah, } \\
\text { sedimen }\end{array}$ & Tidak ditentukan & 5 lab. \\
\hline $\begin{array}{l}2009- \\
2010\end{array}$ & $\begin{array}{l}\text { tanah, } \\
\text { sedimen }\end{array}$ & Tidak ditentukan & \\
\hline \multirow[t]{3}{*}{$\begin{array}{l}2010- \\
2011 \\
\end{array}$} & $\begin{array}{l}\text { tepung } \\
\text { terigu }\end{array}$ & $\begin{array}{l}\text { A: } \mathrm{Al}, \mathrm{K}, \mathrm{Mg}, \mathrm{Mn}, \mathrm{Na} \\
\mathrm{B}: \mathrm{Ca}, \mathrm{Cu}, \mathrm{Fe}, \mathrm{Se}, \mathrm{Zn}\end{array}$ & 6 lab. \\
\hline & $\begin{array}{l}\text { tepung } \\
\text { beras }\end{array}$ & $\begin{array}{l}\text { A: } \mathrm{Al}, \mathrm{K}, \mathrm{Mg}, \mathrm{Mn}, \mathrm{Na} \\
\mathrm{B}: \mathrm{Ca}, \mathrm{Cu}, \mathrm{Fe}, \mathrm{Se}, \mathrm{Zn}\end{array}$ & \\
\hline & sedimen & $\begin{array}{l}\text { A: Al, Co, Cr, Mn, V } \\
\text { B: As, Ca, Fe, Mg, Zn }\end{array}$ & \\
\hline \multirow[t]{4}{*}{$\begin{array}{l}2011- \\
2012 \\
\end{array}$} & Tanah & $\begin{array}{l}\text { A: Ca, Co, K, Sr, Ti } \\
\text { B: Ba, Cr, Cu, Hg, Ni }\end{array}$ & 5 lab \\
\hline & batubara & $\begin{array}{l}\text { A: As, Fe, Mn, U, V } \\
\text { B: Cr, Ni, Se, Th, Zn }\end{array}$ & \\
\hline & $\begin{array}{l}\text { Tepung } \\
\text { terigu }\end{array}$ & $\begin{array}{l}\text { A: } \mathrm{Al}, \mathrm{K}, \mathrm{Mn}, \mathrm{Se}, \mathrm{Zn} \\
\mathrm{B}: \mathrm{Ca}, \mathrm{Cu}, \mathrm{Mg}, \mathrm{Fe}, \mathrm{Na}\end{array}$ & \\
\hline & otot sapi & $\begin{array}{l}\text { A: } \mathrm{Ca}, \mathrm{Mg}, \mathrm{K}, \mathrm{Mn}, \mathrm{Na} \\
\text { B: } \mathrm{Al}, \mathrm{Cu}, \mathrm{Fe}, \mathrm{Mo}, \mathrm{Se}\end{array}$ & \\
\hline \multirow[t]{3}{*}{$\begin{array}{l}2012- \\
2013 \\
\end{array}$} & $\begin{array}{l}\text { Tepung } \\
\text { terigu }\end{array}$ & $\begin{array}{l}\mathrm{A}: \mathrm{Al}, \mathrm{K}, \mathrm{Mn}, \mathrm{Na}, \mathrm{Se} \\
\mathrm{B}: \mathrm{Ca}, \mathrm{Cu}, \mathrm{Fe}, \mathrm{Mg}, \mathrm{Zn}\end{array}$ & 6 lab. \\
\hline & $\begin{array}{l}\text { debu } \\
\text { batubara }\end{array}$ & $\begin{array}{l}\text { A: Fe, K, As, Th, Mn } \\
\text { B: Cr, U, V, Ba, Ti }\end{array}$ & \\
\hline & $\begin{array}{l}\text { darah } \\
\text { binatang }\end{array}$ & $\begin{array}{l}\text { A: } \mathrm{K}, \mathrm{Fe}, \mathrm{Na}, \mathrm{Mg} \\
\mathrm{B}: \mathrm{Ca}, \mathrm{Cu}, \mathrm{Se}, \mathrm{Zn}\end{array}$ & \\
\hline \multirow[t]{2}{*}{2013} & sedimen & $\begin{array}{l}\mathrm{Al}, \mathrm{As}, \mathrm{Cr}, \mathrm{Co}, \mathrm{Fe}, \mathrm{K}, \\
\mathrm{Sb}, \mathrm{Ti}, \mathrm{U}, \mathrm{V} \text { dan } \mathrm{Zn}\end{array}$ & 7 lab \\
\hline & $\begin{array}{l}\text { debu } \\
\text { batubara }\end{array}$ & $\begin{array}{l}\mathrm{Al}, \mathrm{As}, \mathrm{Ba}, \mathrm{Ca}, \mathrm{Cr}, \mathrm{Fe}, \\
\mathrm{Hg}, \mathrm{K}, \mathrm{Mg}, \mathrm{Mn}, \mathrm{Na}, \\
\mathrm{Sb}, \mathrm{Se}, \mathrm{Sr}, \mathrm{Th}, \mathrm{Ti}, \mathrm{U} \\
\text { dan V }\end{array}$ & \\
\hline \multirow[t]{4}{*}{$\begin{array}{l}2015- \\
2016 \\
\end{array}$} & $\begin{array}{l}\text { Cuplikan } \\
1\end{array}$ & $\begin{array}{l}\mathrm{Al}, \mathrm{Ca}, \mathrm{Fe}, \mathrm{Mg}, \\
\mathrm{As}, \mathrm{Cr}, \mathrm{Cu}, \mathrm{Mn}, \mathrm{V}, \mathrm{Zn}\end{array}$ & 4 lab. \\
\hline & 2 & $\begin{array}{l}\mathrm{Al}, \mathrm{Ca}, \mathrm{Fe}, \mathrm{Hg}, \mathrm{Mg}, \\
\mathrm{As}, \mathrm{Cr}, \mathrm{Cu}, \mathrm{Mn}, \mathrm{V}, \mathrm{Zn}\end{array}$ & \\
\hline & 3 & $\begin{array}{l}\mathrm{Al}, \mathrm{Ca}, \mathrm{Fe}, \mathrm{Mg}, \mathrm{K}, \mathrm{Na} \\
\mathrm{Ti}, \\
\mathrm{As}, \mathrm{Sb}, \mathrm{Cr}, \mathrm{Co}, \mathrm{La}, \\
\mathrm{Mn}, \mathrm{Sm}, \mathrm{Sc}, \mathrm{V}, \mathrm{Zn}\end{array}$ & \\
\hline & 4 & $\begin{array}{l}\mathrm{Al}, \mathrm{Ca}, \mathrm{Fe}, \mathrm{Mg}, \mathrm{K}, \mathrm{Na}, \\
\mathrm{Ti}, \\
\mathrm{As}, \mathrm{Sb}, \mathrm{Cr}, \mathrm{Co}, \mathrm{Mn}, \\
\mathrm{V}, \mathrm{Zn} .\end{array}$ & \\
\hline
\end{tabular}

Keterangan:

lab. : laboratorium

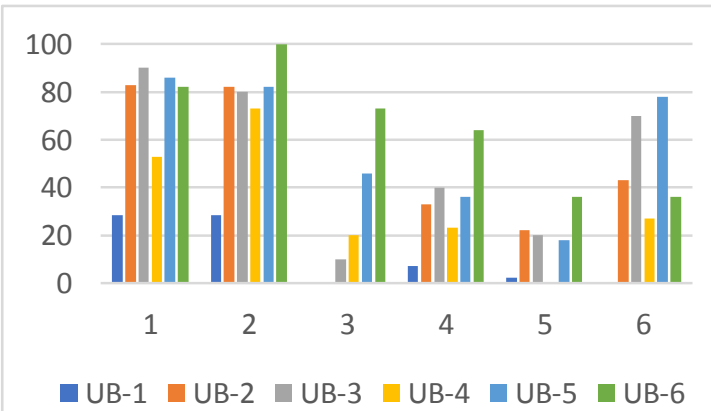

Gambar. 1. Keberterimaan (\%) Pelaporan Uji Banding (UB) 6 Laboratorium

\section{Pertemuan Teknis, Workshop dan Seminar}

Pertemuan Teknis diselenggarakan setiap tahun dan diikuti oleh personel AAN dari semua laboratorium. Beberapa permasalahan yang dibahas dan menghasilkan pemahaman yang sama antara lain:

1. Hasil uji banding: masalah yang dihadapi dalam analisis unsur tertentu, memberikan penyelesaian berupa skema waktu iradiasi, waktu pendinginan, dan waktu pencacahan.

2. Ketidakpastian pengukuran: kesulitan perhitungan dapat diselesaikan dengan penjelasan statistik.

3. Limit deteksi: kesepemahaman untuk perhitungan limit deteksi berdasarkan spektrum gamma dengan metode Currie.

4. Penerapan metode $K_{0}$ : dengan memberikan contoh kasus oleh laboratorium yang sudah menerapkan

Workshop secara umum juga diselenggarakan setiap tahun. Beberapa workshop dengan pembicara ekspert dari IAEA membahas tentang Utilization of Nuclear Reactor. Dalam workshop tersebut diidentifikasi potensi untuk pengembangan AAN Epithermal. Pada workshop berikutnya dibahas tentang pengembangan fasilitas iradiasi yang ada di Reaktor Serpong untuk AAN epitermal, serta teknik untuk pelaksanaannya. Tindak lanjut dari kegiatan tersebut berupa pengiriman beberapa personel untuk mengikuti pelatihan teknik pelaksanaan AAN epitermal di luar negeri.

Seminar untuk topik AAN tergabung dalam Seminar Nasional Teknik Analisis Nuklir (TAN) diselenggarakan tahun 2008 sampai dengan 2015. Penyelenggaraan Seminar oleh kelompok AAN dilakukan secara bergantian yang terbagi sesuai area, yaitu Serpong, Bandung, Yogyakarta, dan Pasar Jumat, sehingga semua kelompok terlibat aktif dalam penyelenggaraan Seminar. Topik Seminar dari tahun ke tahun berkembang dan meningkat, seperti "Penerapan TAN dalam Bidang Industri, Lingkungan dan Kesehatan", yang meningkat dalam tahun selanjutnya menjadi "Peningkatan Peran TAN dalam Bidang Industri, Lingkungan dan Kesehatan" [18]. Dengan peran aktif semua personel dari semua kelompok AAN, maka Seminar TAN memberikan kontribusi dalam pengembangan kompetensi personel AAN. Seminar Nasional 
TAN juga dirangkai dengan workshop untuk peserta luar BATAN, supaya lebih mengenal pemanfaatan teknik analisis nuklir. Dari kegiatan tersebut terjalin kerjasama pemanfaatannya antara lain dengan Badan Lingkungan Hidup Daerah, Kementerian Pertanian, dan Kementerian Kesehatan.

\section{e-Learning}

Pada Pelatihan yang diselenggarakan tahun 2017, penyampaian materi dilakukan menggunakan gabungan metode tatap muka dan e-learning. Delapan belas materi disampaikan melalui e-learning dengan modul yang ditempatkan pada sistem e-learning Pusdiklat. Modul disusun oleh para pengajar. Pada hari pertama tatap muka, dijadwalkan review materi yang sudah dipelajari secara $e$ learning. Materi e-learning tersebut dapat terus dimanfaatkan apabila diperlukan.

Modul e-learning IAEA (e-learning tool for NAA) terdiri dari 6 kelompok sebagai berikut [17]:

1. Introduction, History, Application: 3 modul dan 3 set Quiz

2. Basic Nuclear Physics: 8 modul dan 8 set Quiz

3. Calibration: 5 modul dan 5 set Quiz

4. Instrumentation: 7 modul dan 7 set Quiz

5. Quality Assurance and Quality Control: 9 modul, 6 set Quiz dan 3 case study

6. Practical Excercises: 8 modul dan 6 set Quiz

Pengembangan modul tersebut sudah dilakukan beberapa kali melalui workshop yang melibatkan personel AAN dari sekitar 50 negara. Modul tersebut lebih lengkap dibandingkan dengan modul Pelatihan Petugas AAN, sehingga bisa dimanfaatkan untuk pengembangan kompetensi pada tingkat yang lebih tinggi, seperti analisis permasalahan yang sering terjadi pada AAN untuk jenis sampel tertentu. e-Learning tool for NAA dapat diakses melalui IAEA Learning Management System (elearning.iaea.org) yang merupakan bagian dari laman IAEA.

\section{KESIMPULAN}

Pengembangan SDM AAN di BATAN telah dilakukan melalui Pelatihan, Sertifikasi
Petugas AAN, Uji Banding, Pertemuan Teknis, Workshop, dan Seminar. Pengembangan SDM pada tahap yang lebih tinggi dapat memanfaatkan e-learning tool of NAA yang telah diluncurkan oleh IAEA. .

Model pengembangan SDM AAN tersebut perlu dipertahankan untuk menjamin kompetensi SDM AAN di BATAN, karena jumlah personel terbatas dan adanya kesenjangan kompetensi dengan personel yang relatif masih baru. Model pengembangan SDM tersebut sangat mendukung pengelolaan pengetahuan nuklir, sehingga dapat diterapkan pada semua bidang kenukliran.

\section{UCAPAN TERIMAKASIH}

Ucapan terimakasih disampaikan kepada Drs. Saeful Yusuf, MT., atas bantuan menyediakan data Uji Banding.

\section{DAFTAR PUSTAKA}

1. Pusdiklat BATAN, "Laporan Penyelenggaraan Pelatihn Penyelia Laboratorium AAN", 2003.

2. Pusdiklat BATAN, "Laporan Penyelenggaraan Pelatihan Metode AAN K " , 2006.

3. Pusdiklat BATAN, "Laporan Penyelenggaraan Pelatihan Validasi Metode AAN $\mathrm{K}_{0}$ ", 2007.

4. Pusdiklat BATAN, "Laporan Penyelenggaraan Pelatihan Coaching: Komputasi Pemodelan AAN Instrumental $\mathrm{K}_{0}$ ", 2009.

5. Pusdiklat BATAN, "Laporan Penyelenggaraan Coaching: Validasi Metode AAN " , 2009.

6. Pusdiklat BATAN, "Laporan Penyelenggaraan Pelatihan untuk Teknisi AAN ", 2011.

7. Pusdiklat BATAN, "Laporan Penyelenggaraan Pelatihan untuk Penyelia AAN " , 2012.

8. Pusdiklat BATAN, "Laporan Penyelenggaraan Pelatihan Penyegaran Petugas AAN ", 2015.

9. Pusdiklat BATAN, "Laporan Penyelenggaraan Pelatihan Petugas AAN ", 2017.

10. BATAN, SB 007-BATAN: 2009, "Kualifikasi dan Sertifikasi Petugas Analisis Aktivasi Neutron".

11. BATAN, "Laporan Uji Banding 1", 2009. 
12. BATAN, "Laporan Uji Banding 2", 2010.

13. BATAN, "Laporan Uji Banding 3", 2011.

14. BATAN, "Laporan Uji Banding 4", 2012.

15. BATAN, "Laporan Uji Banding 5", 2013.

16. BATAN, "Laporan Uji Banding 6", 2014.

17. IAEA, "Meeting report: Training Workshop on E-learning Tools for Neutron Activation Analysis", 2016.

18. BATAN. "Laporan Pelaksanaan Seminar Teknik Analisis Nuklir", 2011. 